\title{
Violence in Cross-cultural Relations as the Outcome of Specific Cognitive and Emotional Processes
}

\author{
Camilla Pagani* \\ Institute of Cognitive Sciences and Technologies, National Research Council, Roma, Italy
}

\begin{abstract}
Violence, including psychological violence, sometimes negatively characterizes cross-cultural relations in western societies, especially in those countries that have become the destination of substantial immigration flows in the last few decades and where the relationship with diversity affects many significant aspects of people's lives. In these cases violence, which can also be labeled as racism, is the outcome of specific cognitive and emotional processes. Among these processes perceived threat, fear, hate, and resentment play a major role, though other cognitive and emotional factors, such as ignorance, envy, and jealousy are also important. As to threat, a distinction is made between "justified", "partly justified" and "unjustified" threat, and the relation between perceived threat and knowledge (and lack thereof) is also considered. Since the concept of threat and the concept of fear are interdependent, specific fears are especially described, mainly fear for one's safety, fear for one's welfare, and fear to lose one's identity. Perceived threat is also considered in its interconnections, especially as far as the relationship between the individual level and the macro-level (historical, juridical, economic, political, socio-cultural) is concerned. These theoretical considerations are supported by the analysis of some qualitative data which are drawn from two research studies we conducted on youths aged 9-18 with the use of interviews and of anonymous open-ended essays. A few suggestions for educational interventions aiming to prevent, reduce, or eliminate violence in cross-cultural relations are presented.
\end{abstract}

Keywords: Violence, cross-cultural relations, cognitive and emotional processes.

\section{INTRODUCTION}

Violence, including psychological violence, sometimes negatively characterizes cross-cultural relations in western societies, especially in those countries that have become the destination of substantial immigration flows in the last few decades and where the relationship with diversity affects many significant aspects of people's lives. In these cases, violence, which can also be labeled as racism, is the outcome of specific cognitive and emotional processes. Among these processes perceived threat, fear, hate, and resentment play a major role, though other cognitive and emotional factors, such as envy, jealousy, and lack or dearth of knowledge are also important. In this paper I will try to track and, at least in part, analyze some of the most relevant psychological processes associated with youngsters' racist attitudes. Obviously, here I will consider not only the expressions of overt, direct racism but also of the so-called "aversive racism" [1-3], which relates to subtler and more complex forms of bias. This point is important also as far as methodological issues are concerned. As we will see, most of my considerations will be drawn from qualitative data my colleagues and I obtained in two studies through interviews and open-ended essays. Since aversive racism generally implies a dissociation between the cognitive and emotional components of racial attitudes, namely "a conflict between the denial of personal prejudice and underlying unconscious negative

\footnotetext{
*Address correspondence to this author at the Institute of Cognitive Sciences and Technologies, National Research Council, Roma, Italy;

Tel: 003906 44595311; Fax: 003906 44595243;

E-mail: camilla.pagani@istc.cnr.it
}

feelings" ([3], p.214), it is clear that the identification and understanding of these forms of bias require a more profound, complex, and attentive analysis of data. Though interviews and open-ended essays are different instruments, they certainly share many elements. Hence, I can say with confidence that in both cases in analyzing data we aimed to reach the implicit/latent and not only the explicit/manifest meaning of the texts, thus allowing us to more easily identify also subtler forms of racism and some of the fundamental motivations underlying them.

\section{MATERIALS AND METHODOLOGY}

Two studies were carried out. In the first study we used anonymous open-ended essays aiming to tap the attitudes of pre-adolescents and adolescents toward diversity and multiculturalism. Eleven state school were involved: two primary schools, five middle schools and four high schools. The schools were located in central Italy (nine in Rome, one in a small town in the vicinity of Rome and one in a small town in the province of Florence). All the classes participated in the research and, consequently, participation was not limited to volunteering participants. The author explained the aims of the study to the pupils and presented their participation as one of the various normal activities of the school on that particular day and as a part of the school curriculum. Consequently, only school administration approval was required. From the total number of essays we obtained, we randomly selected 350 essays, on the basis of gender, estimated age and school (176 females and 174 males, aged 9-18 years).

The essays were written at school. Each pupil received a brief note with the following instructions: 
Italy is a country inhabited by many Italians as well as by many immigrants. We do not know if you are an Italian or an immigrant. In any case, we are interested in what you think about this topic. Tell us about your experiences and the experiences of others, both at school and outside school.

Participants were asked to indicate only their gender. Their age could be inferred from the grades they were attending, as their essays were collected separately from each class.

In the second study, we conducted five focus groups with small groups of youngsters (about 10 participants each group, both males and females, aged 15-18, from 3 state schools in Central Italy, none of which was involved in the first study, one in Rome and two in two different small towns). Also in this case, participation in the research was presented as part of the school curriculum.

The aim of this study was to further deepen the understanding of some of the basic cognitive and emotional processes associated with youth's racist attitudes. Pupils were presented with the following question which was meant to prompt the discussion and to be the object of the discussion itself:

How do you feel about the fact that probably more and more in the future we and people from other countries and cultures will live together?

All the essays and the interviews were independently examined by the author and two research assistants, who conducted a qualitative and quantitative analysis of the texts and, successively, discussed the results of their analyses. The methodology used was largely based on principles of textual analysis, discourse analysis, ethnographic analysis, and content analysis [4-7]. An evaluation of the essays in terms of their structure and coherence [8] was also conducted. This way, our analysis was the result of a thorough and integrated examination of: a) the contents of the texts according to topics or semantic fields; b) the style of discourse, namely of more formal aspects of the texts; c) the context (historical, social, and psychological), both at the micro level (participants' schools) and at the macro level (society at large), in which the essays were produced. Through this integrated approach we aimed to understand, whenever possible, the implicit as well as the explicit, meaning of the texts $[9,10]$. We believed that this would greatly help us obtain a deeper and wider knowledge of preadolescents' and adolescents' cognitions and emotions relating to their attitudes toward multiculturalism and, in particular, to their non-acceptance or scarce acceptance of diversity.

I will provide here only a few examples of the numerous categories we identified as far as the content analysis proper is concerned, namely "cross-cultural friendships", "the media", "presence of immigrant pupils in participants' schools", "contradiction" (a category which refers to those cases where participants declare they dislike immigrants but also state they are friendly, or even very friendly, with an immigrant peer) and "Italian emigration in the past". As to more formal aspects of the texts, we identified categories such as "coherence", "complexity", "correctness", and "concreteness". In the analysis of the psychological, social, and political contexts, among other things, we considered participants' views regarding the quality of cross-cultural relations in their schools, and participants' reference to governmental policies as far as immigration is concerned. With regard to participants' cognitions and emotions, we evaluated, for example, participants' level (using a five-point Likert scale) of racist attitudes, of contradiction in their attitudes, of fear toward immigrants, and of empathy toward outgroups in crosscultural relations.

\section{PERCEPTION OF THREAT}

In previous papers I analyzed the role of perceived threat, of fear, and of knowledge (and lack thereof, namely ignorance) in the refusal or scarce acceptance of diversity in cross-cultural relations [11-14]. Here I will only mention the distinction we made between perceived justified threat (i.e., rational and grounded on real, concrete, and verifiable circumstances), unjustified threat (irrational, imaginary), and partly justified threat. This distinction, which is seldom made in this research area (for an exception, see Stephan et al., [15]), is particularly important as some psychological processes underlying these different kinds of threat differ in various ways. For example, in the case of the perception of unjustified or partly justified threat there is generally a relation between this perception and a lack or dearth of knowledge, and, hence, very often, between this perception and prejudices.

It is also important to point out that, while the perception of a justified threat is an adaptive phenomenon as it allows to tackle dangers, the perception of an unjustified or partly justified threat is anything but adaptive. A very simple example can be provided by the animal world. If a gazelle feels threatened by the proximity of a lion, and the lion is actually there, the gazelle runs away and this way the animal's life is saved. If the lion is not there the perception of the threat drives the gazelle to a useless flight, while the animal could have continued to graze in the savannah. In natives' relationships with immigrants the perception of an unjustified or partially justified threat is seriously harmful at various levels: from the level, for example, of social life and fundamental rights to the level of the psychological, physical, and economic well-being of each individual (both native and immigrant).

We also identified some specific fears relating to youth's perception of threat in cross-cultural relations, namely: a) fear for their safety and for their welfare, b) fear to lose their identity, and c) fear to lose other people's affection [14]. I maintain that the importance of motivations b) and c) has been underestimated by researchers and educators. Obviously, the connotations and the level of strength of each of these kinds of fear can vary. Suffice it to quote these two examples drawn from two adolescents' open-ended essays, both relating to fear to lose their identity. The former example may indicate a more or less vague feeling of disquiet, while the latter is a clear expression of overt and direct racism and is almost certainly permeated with hate ${ }^{1}$ :

'In the quotations from pupils' essays we did not eliminate spelling, grammatical,
syntactic, or lexical mistakes. 
(boy, 13 years) On the 1st of May last, in the centre of Empoli [a small town in Tuscany] there were more Albanians than natives, it seemed as if we were in Tirana.

(boy, 18 years) Personally, I believe that very shortly the race will mix and $I$ do not think it is good, because ITALY must be made up of ITALIANS.

\section{HATE AND PERCEPTION OF THREAT}

This last quotation can usefully help us introduce the issue of the role hate may play in the perception of threat and in violence in cross-cultural relations.

According to Royzman, McCauley, \& Rozin [16] there currently exists no generally accepted definition of hate. However, I will try to specify what I mean by hate when I use this term in this paper and, more in general, when I use it within the context of violence in cross-cultural relations.

The most general and synthetic definition of hate is provided by the Oxford Dictionary of English [17], which describes hate as "intense dislike". Allport's [18] definition is more expanded, as he describes hate as an emotion of extreme dislike or aggressive impulses toward a person or group of persons. In the Penguin Dictionary of Psychology Reber [19] defines hate as "a deep, enduring, intense emotion expressing animosity, anger and hostility toward a person, group or object". Here the stress is on the intensity, persistence, and depth of the emotion and on its possible and frequent relation to "passion", which expresses itself as anger and aggression.

It is important to point out that relatively recent research defines emotion as a set of "multicomponent response tendencies that unfold over relatively short time spans" ([20], p. $125)$, thus attaching to emotion an episodic rather than a dispositional quality [16]. Indeed, a distinction should be made between episodic emotions and episodic dispositions, the latter being considered as "relatively long-term tendencies to emote (in the sense of displaying a distinct episodic emotion)" ([16], p. 5). It is clear that in Reber's definition hate is viewed as an episodic disposition, while other authors (e.g., Beck [21]), as well as many laypersons, conceive of hate both as an episodic disposition and an episodic emotion.

Shand [22] describes love and hate as structurally equivalent opposites, being hate the exact antinomy of love. While love implies a positive correspondence and identification between the emotions of the person who loves and the fortunes of the person who is loved, hate implies a symmetrical negative correspondence. Hate (and love) is viewed by Shand as a syndrome, namely as a group of episodic dispositions.

In line with Shand's perspective, McCauley [23] describes love as the syndrome of "positive identification", so that its opposite - hate - could be considered as the syndrome of "negative identification" [16]. More recently Ekman [24] has put forward a concept of hate that is closely akin to Shand's [22] concept of love as syndrome. Ekman

2I will later examine the concept of "passion" within the context of Sternberg's theory of hate $[25,26]$ maintains that hate is not an emotion but an "emotional attitude", which is an affective phenomenon involving more than one emotion and which is an episodic disposition rather than a particular episodic emotion.

Finally, I will mention Sternberg's theory of hate $[25,26]$. There are important points in this theory, some of which I will very briefly touch on. Sternberg named his theory "duplex" and "triangular". It is "duplex" because it applies to both individuals and groups. Indeed, he states that scientific evidence suggests that "the basic processing system that applies to the formation and processing of impressions about groups and about individuals is the same" ([26], p. 38). It is triangular because in his view hate comprises three components. Sternberg maintains that hate is "very closely related psychologically to love" ([26], p. 38), that it "has its origins in stories that characterize the target of the emotion" (ibid., p. 38), and that it presents a triangular structure generated by these stories.

The three components of this structure are: negation of intimacy, passion, and commitment. Negation of intimacy implies the seeking of distance. Passion is displayed through anger or fear provoked by a threat. Commitment, which means commitment to false ideas, involves cognitions of devaluation. Devaluation often expresses itself through contempt for the targeted individual or group, who may even be considered as subhuman. These three components are very often generated and/or fuelled by "hate propaganda" through the creation and diffusion of story themes, which contribute to producing false judgments, thus thwarting the development of people's critical thinking processes. In these stories the perception of threat plays a major role. Threat is the expression of a dynamic, complex, and multi-faceted set of ideas. According to Sternberg [26] the propaganda can originate, for example, from the family, the media, politicians, age mates, school, and other sources of information, so that he comes to the important conclusion that "to a large extent, [...] hate is learned" ([26], p. 42). People sometimes create stories in order to find self-esteem by devaluing others. According to Royzman, McCauley, \& Rozin [16], devaluation of a target group can also be the result of a rationalization of a pre-existing set of negative attitudes and behaviors, corresponding to what they define "pattern of inverse caring" (p. 24), toward that group. Politicians can impute the origin of their difficulties to an external target so as to justify their misdeeds and errors.

In this paper the meaning I attach to the word "hate" can be described by the following propositions: a) hate is an episodic disposition; b) hate can be related to perception of threat, fear, misunderstanding, lack or dearth of knowledge, resentment, and frustration; c) hate is fuelled and often generated by "stories"; d) the competitive life pattern which prevails in our society provides a fertile breeding ground for the development of hate; e) hate can sometimes be generated and/or fuelled by the realization that the targeted individual or group is actually superior (i.e., more honest, more capable) as compared to the hater or the group the hater belongs to and in these cases hate can be accompanied by envy. 
Hate can sometimes be associated with resentment, as also our data indicate. Resentment is a psychological state resulting from more or less controlled feelings of anger at having being treated unfairly or at believing one has been treated unfairly. Resentment is frequent in our participants' hostile attitudes toward immigrants. What kind of wrongs do these youth believe they are subjected to at the hands of immigrants so as to think they are the victims and all immigrants, or many/some of them, are the perpetrators? Before answering this question, we have to take a few steps backwards.

Though in our society for many people immigrants certainly represent a threat to what we can roughly describe as an "optimistic view of the world", at the same time, together with other weak categories, like the poor or the handicapped, they provide a great opportunity to just as many people, namely the opportunity to feel somehow superior with respect to an outgroup and, thus, to preserve and strengthen their self-esteem. This way, a primitive, short-sighted, and neurotic need is satisfied. An almost similar point of view is expressed by Blumer [27], when he writes that race prejudice is a defensive reaction to the challenging of the sense of group position and that it has the protective, though myopic, function of preserving the integrity and position of the dominant group. But another need, which is usually deeply felt by the young, can also be satisfied in some cases: the need to build and/or preserve the sense of one's (poor) identity through a distinction from and opposition to an outgroup, being both the distinction and the opposition particularly strong and more or less pervaded by hate. Indeed, one of the worst consequences of a competitive life pattern is that most people erroneously believe that individuation can only be developed through contraposition and competition, and not, for example, through cooperation [28].

Therefore, when the immigrant fails to meet these expectations whereby she/he should play the role of the inferior person, and appears to be, for instance and according to cases, more powerful, more skilled, or more honest than most members of the majority group, anger, fear, frustration, hate, resentment, and envy may arise on the part of some members of this group.

\section{ANALYSIS OF SOME EXAMPLES DRAWN FROM OUR TWO RESEARCH STUDIES}

\section{Immigrants who want to show they are Superior or who are Actually Superior, as Compared to Natives}

Three examples can be drawn from our data, the first from an open-ended essay, and the other two from a focus group $^{3}$. As to the second example, we will see that some students' opinion that Muslims who live in Italy are "better" than Italian Catholics is associated with these students' anger and hostility toward Muslims.

(boy, 13 years) I hate those immigrants who want to boss around in a host country, they want to rule the roost.

${ }^{3}$ Only when the quotations are preceded by a capital letter (which stands for participant's name), these quotations are drawn from focus groups. In all the other cases the quotations are drawn from open-ended essays.
A (girl): [...] a Muslim, for example, has more religious faith than us [...].

E (girl): [...] if Muslims believe in God more than us it's because they have a good grounding instead, we have a Pope $[\ldots]$.

$\mathrm{H}$ (boy): [...] how many people go to Mass on Sundays? No one. There's the football match, there's ...

A (girl): It's because in Italy the Church stinks.

E (girl): At least they [Muslims] believe, because they have some principles but who respects the Bible? No one. Instead, they have..., their religion is completely different, they have some principles. Instead, we have nothing.

[A female participant (E) is talking about a Filipino girl who is particularly smart. Another female participant (L) is suggesting that E may feel some envy for her.]

E (girl): Because in any case we are biased, because she came from the Philippines and I said: "Well, anyway, she comes from a country which is not as developed as ours". I am biased. Then when I found out she is more clever than me I became envious.

A (girl): We don't even want to learn things from her. For example, if she knows more things than me, I put a distance between her and myself, I don't listen to her, I don't say to her "Teach me how to do it".

\section{The Role of Stories}

As I said above, hate, resentment, fear, and envy can be generated and/or fuelled by "stories" regarding immigrants as a whole or some of them, though I believe that at the same time all these psychological states can in some cases contribute to the creation, enrichment, and dissemination of "stories". It goes without saying that "stories" are usually "concentrates" of prejudices. In the first part of the focus group, from which I have drawn some excerpts for quotation, participants had apparently shown a tolerant, objective, and serene disposition while discussing multiculturalism and their relations with immigrants. A girl had even stated that she has a Croatian boyfriend and a boy had said that his parents have long distance adopted a black child. Later, somehow (it would take too much space here to put forward some hypotheses as to the reason why this attitude changed) participants began to display a more hostile disposition toward immigrants, which was fundamentally related to participants' perception of what could be roughly defined as some immigrants' "provocative and bossy attitude" in a country that "hosts" them. In particular, most participants harshly criticized and attacked Muslims living in Italy for demanding that the crucifix be removed from Italian schools. A girl's protest was especially vehement and she sometimes spoke as if she was addressing an imaginary Muslim:

E (girl): You have arrived in my town. You have to adapt to my religion. I don't mean you have to give up your religion, but at school I want to have the crucifix, because $100 \%$ of Italians are Christians. 
Here, two "stories" have come to light. The former regards Muslims' purported request that the crucifix should be removed from schools. The latter regards the percentage of Christians in the Italian population. It is a fact that in the last few decades criticism against the presence of the crucifix in public places has not come from Muslims. It has come from people who believe in the principles of laicism and in the respect of people of different religions and of those who have no religion at all (e.g., Mola, [29]). Besides, it is obvious that the totality of Italians is not constituted by Christians.

Moreover, not only Muslims but also all immigrants can be harshly criticized by some participants on account of their alleged ingratitude toward a "hosting" country.

(girl, 15 years) I would like to catch them and then thrash them and, later on, send them back to their own country, since they dare do this to us, though we even host them in our country.

(boy, 16 years) Some Italians die on account of these people. It is our fault, not theirs, because we hire them. We give them everything; [...] Not to mention Polish immigrants! I'd better leave it! I would roast all of them! We are damn fool! Instead of hosting them, we should kick their arses out! [...] P.S. Death to immigrants!

But hate, resentment, and envy are activated and/or fed by other "stories" as well. For example, some people, including a few of our participants (as the quotations below from some essays indicate), erroneously believe that immigrants are even granted privileges by the Italian government (this fact being often considered by some participants as one of the main causes, or even the main cause, of social and economic problems in Italy):

(girl, 15 years) [...] there are still some people who live in caravans and containers since the time of the earthquake, instead there are these immigrants that have apartments, even large ones, and also big and expensive cars.

(boy, 18 years) They stroll with beers and knives, at leisure in town. I get mad when I think that if I, an honest Italian, behave badly as they do, I am in trouble all my life, and they, after five minutes are already out of jail drinking beer ${ }^{4}$.

(boy, 18 years) They are loafers, and what is more they are also privileged and protected by the Italian government. filthy:

Other participants wrongly believe that immigrants are

(boy, 18 years) They throng the buses and the subway, so we always travel in uncomfortable conditions, they smell, because they don't wash themselves.

${ }^{4}$ In Italy, immigrants constitute the thirty-eight per cent of the jail population (http://www.programmaintegra.it/modules/news/article.php? storyid=3234). (boy, 15 years) The most annoying thing is the stink they carry with them and often, even in winter, we are compelled to keep the windows down when we travel, so as to avoid feeling sick.

(boy, 14 years) I think that since a lot of immigrants have begun to arrive in Italy they have brought diseases and filth etc."

(boy, 16 years) [...] they spoil the cities everywhere and even the aesthetics [...]

Others believe that immigrants are overwhelmingly numerous and view immigration as the invasion of a barbarian horde:

(boy, 15 years) Now in Italy there are more immigrants than Italians $[\ldots]$

(girl, 12 years) I hope that, eventually, it will not be our turn to move away.

(boy, 14 years) Indeed, it cannot be denied that our coasts have almost daily been harassed by the arrival of these boats [...]

(boy, 14 years) Unfortunately, Italy has become a "colony" for immigrants and an easily accessible one.

Others, like the boy of 18 (see quotation above) who thinks that, due to immigration flows, a supposed "Italian race" will mix, not only believe in the concept of race, which is scientifically incorrect, but also believe in the possibility for this "race" to be contaminated by immigrants' presence.

And, finally, many believe in stories that equate immigration with criminality.

(girl, 13 years) Almost all the immigrants are all paedophiles, who rape girls in the subway, in parks, and in many other places. [...] this way they ruin many girls' lives as they infect them with ADS. [participant meant "Aids"]

(girl, 16 years) I would like to live a bit better and quieter life, without being persecuted by the idea of being assaulted and robbed by these immigrants.

(boy, 13 years) Almost all illegal immigrants behave badly (they steal, destroy other people's things, and even kill).

(boy, 14 years). I believe that these immigrants are a ruin for Italy except $1 \%$ of them who come here to find a job instead the large majority arrive here to push, to steal, or to work under the counter.

\section{CONCLUSIONS}

I would like to conclude my paper with a quotation from an essay, followed by some brief considerations and by a final quotation from another essay:

(girl, 12 years) I believe that when immigrants come here illegally by sea etc. ... they should be sent back to their own country. Yes, because if they had been respectable people, they should not have come here illegally. Personally, I have had no direct experience 
with immigrants. I mean, I may know some of them by sight, but I have never exchanged opinions with them.

This girl has never known an immigrant but her opinions on immigrants are clear-cut and, what is of even greater concern, she appears to have wrong information about the phenomenon of immigration, especially when she states that it is impossible for an illegal immigrant to be a respectable person. It goes without saying that in this context school could certainly play a major role [12].

It thus follows that youth should be provided with correct and thorough information and should also possibly experience a direct positive contact with immigrants (e.g., Allport, [18], Pettigrew [30-32]).

In other papers I have underlined the role of school as well as the role of the macro socio-political-cultural context in affecting youth's cross-cultural relations [11-14]. In particular, as regards the role of school, it goes without saying that school can potentially provide an excellent opportunity for the development of a durable positive contact among pupils from different cultures. And, most importantly, a durable positive contact can provide pupils with the precious opportunity to become friends. Both Allport [18] and Pettigrew [30-32] underscored the positive role played by intergroup close friendships. In fact, Pettigrew [31] maintained that a fifth condition (the other four conditions being "equal group status within the situation", "the existence of common goals", "social support", and "intergroup cooperation") is required for the contact hypothesis [18], namely the contact situation must provide participants with the opportunity to become friends. Pettigrew [30] demonstrated that intergroup friendship is a strong predictor of reduced prejudice and of proimmigrant policy preferences and that intergroup friendship and diminished prejudice generalize to more positive attitudes toward other outgroups in general, even toward outgroups with whom there has been no contact.

Finally, as also Esses and Dovidio's [33] research findings indicate, youth should also be encouraged to identify and analyze their emotions while addressing such social problems like discrimination and racism. Emotions belong to a deeper and more complex level as compared to knowledge and, with the contribution of good educators, they could surface with no great effort. Acquiring knowledge, identifying and analyzing emotions, and developing positive affective relations with educators are essential components in any attempt to tackle violence and racism. This is also suggested by one of our participants who wrote:

(girl, 17 years) I would like to launch this appeal: provide youth with information and liberate them from the horrible roots which make them sink into their prejudices. Speak to them calmly and we will listen to you.

\section{CONFLICTS OF INTEREST}

None Declared

[14] Pagani C, Robustelli F. Young people, multiculturalism, and education for empathy. Int Soc Sci J 2010; 200/201: 247-61.

[15] Stephan WG, Ybarra O, Bachman G. Prejudice toward immigrants. J Appl Soc Psychol 1999; 29: 2221-37.

[16] Royzman EB, McCauley C, Rozin P. From Plato to Putnam: four ways to think about hate. In: Sternberg RJ, Ed. The psychology of hate. Washington, DC: American Psychological Association 2005; pp. 3-35.

[17] Oxford Dictionary of English. Oxford: Oxford University Press 2006.

[18] Allport GW. The nature of prejudice. Cambridge, MA: AddisonWesley 1954.

[19] Reber. The Penguin dictionary of psychology. Penguin 1985.

[20] Friedrickson BL, Branigan C. Positive emotions. In: Mayne TJ, Bonanno GA, Eds. Emotions: current issues and directions. New York: Guilford Press 2001; pp. 123-51.

[21] Beck AT. Prisoners of hate: the cognitive basis of anger, hostility, and violence. New York: Harper Collins 1999.

[22] Shand AF. The foundations of character. $2^{\text {nd }}$ ed. London: MacMillan 1920.

[23] McCauley C. The psychology of group identification and the power of ethnic nationalism. In: Chirot D, Seligman M, Eds. Ethnopolitical warfare: causes, consequences, and possible solutions. Washington, DC: American Psychological Association 2001; pp. 343-62.

None Declared 
[24] Ekman P. An argument for basic emotions. Cognit Emotion 1992; 6: 169-200.

[25] Sternberg RJ. A duplex theory of hate and its development and its application to terrorism, massacres, and genocides. Rev Gen Psychol 2003; 7: 299-328.

[26] Sternberg RJ. Understanding and combating hate. In: Sternberg RJ, Ed. The psychology of hate. Washington, DC: American Psychological Association 2005; pp. 37-49.

[27] Blumer H. Race prejudice as a sense of group position. Pac Sociol Rev 1958; 1: 3-7.

[28] Robustelli F, Pagani C. L'educazione contro la violenza. Psicologia Contemporanea 1996; 136: 4-10.
[29] Mola G. Crocifisso obbligatorio in aula. "Nessun decreto del governo". La Repubblica $27^{\text {th }}$ September, 2002.

[30] Pettigrew TF. Generalized intergroup contact effects on prejudice. Person Soc Psychol Bull 1997; 23: 173-85.

[31] Pettygrew TF. Intergroup contact theory. Ann Rev Psychol 1998; 49: 65-85.

[32] Pettygrew TF. Future directions for intergroup contact theory and research. Int J Intercult Relat 2008; 32: 187-99.

[33] Esses VM, Dovidio JF. The role of emotions in determining willingness to engage in intergroup contact. Pers Soc Psychol Bull 2002; 28: 1202-14.

(C) Camilla Pagani; Licensee Bentham Open .

This is an open access article licensed under the terms of the Creative Commons Attribution Non-Commercial License (http://creativecommons.org/licenses/by-nc/3.0/) which permits unrestricted, non-commercial use, distribution and reproduction in any medium, provided the work is properly cited. 